\title{
Modulation of inflammatory and oxidative status by exercise attenuates cardiac morphofunctional remodeling in experimental Chagas cardiomyopathy
}

\author{
Rômulo D. Novaes a,b,*, Reggiani V. Gonçalves ${ }^{c}$, Arlete R. Penitente ${ }^{\mathrm{b}}$, Luiz Henrique M. Bozi ${ }^{\mathrm{d}}$, Clóvis A. Neves ${ }^{\mathrm{e}}$, \\ Izabel R.S.C. Maldonado ${ }^{\mathrm{e}}$, Antônio J. Natali ${ }^{\mathrm{f}}$, André Talvani ${ }^{\mathrm{b}}$
}

a Institute of Biomedical Sciences, Department of Structural Biology, Federal University of Alfenas, 37130-000 MG, Brazil

${ }^{\mathrm{b}}$ Department of Biological Sciences and NUPEB, Federal University of Ouro Preto, 35400-000 MG, Brazil

c Department of Animal Biology, Federal University of Viçosa, 36570-000 MG, Brazil

d School of Physical Education and Sport, University of São Paulo, 05508-030 SP, Brazil

e Department of General Biology, Federal University of Viçosa, 36570-000 MG, Brazil

${ }^{\mathrm{f}}$ Department of Physical Education, Federal University of Viçosa, 36570-000 MG, Brazil

\section{A R T I C L E I N F O}

\section{Article history:}

Received 2 December 2015

Received in revised form 20 March 2016

Accepted 28 March 2016

Available online 31 March 2016

\section{Keywords:}

Animal model

Cardiovascular pathology

Chagas disease

Histopathology

Trypanosoma cruzi

\begin{abstract}
A B S T R A C T
Aims: The rational basis that explains the benefits of exercise therapy on Chagas cardiomyopathy $(\mathrm{ChC})$ is poorly understood. This study investigated the impact of an exercise program on exercise performance, heart parasitism, immunoinflammatory response, fibrogenesis, oxidative damage, and cardiomyocytes contractility in experimental ChC.

Main methods: Wistar rats were subjected to a 9-week treadmill running training and challenged with Trypanosoma cruzi. Control animals remained sedentary. Physical and metabolic performance, cardiac morphology, cytokines, chemokines, nitric oxide, oxidative tissue damage, cardiomyocyte morphology and contractility were analyzed.

Key findings: Exercise training was efficient to improve physical performance and anaerobic threshold in trained animals. By increasing cardiac and serum levels of cytokines (TNF- $\alpha$, IFN- $\gamma$, and IL-6), chemokines (MCP- 1 and CX3CL1), the myocardial activity catalase and superoxide dismutase, and reducing lipid and protein oxidation in cardiac tissue, exercise training seem to be a beneficial strategy to mitigate the progression and severity of Chagas-associated cardiomyopathy.

Significance: The protective adaptations to the host triggered by exercise training contributed to reduce cardiac parasitism, inflammation, fibrosis and cardiomyocytes atrophy. Although exercise training does not affect nitric oxide levels in cardiac tissue from infected animals, this strategy enhanced the efficiency of endogenous antioxidant mechanisms, restricting oxidative tissue damage with positive repercussions to cardiomyocytes biomechanics in rats.
\end{abstract}

(C) 2016 Elsevier Inc. All rights reserved.

\section{Introduction}

Chagas disease caused by the hemoflagellate protozoan Trypanosoma cruzi represents a neglected disease worldwide [1,2]. At the moment, Chagas disease has no cure after T. cruzi spreads and parasitizes multiple organs of the vertebrate host [2,3]. Infectious

Abbreviations: CAT, catalase; ChC, Chagas cardiomyopathy; CX3CL1, chemokine C-X3C Motif Ligand 1; ELISA, enzyme-linked immunosorbent assay; IFN- $\gamma$, interferon gamma; IL-6, interleukin 6; LT, lactate threshold; LV, left ventricle; MDA, malondialdehyde; MCP-1, monocyte chemoattractant protein-1; NO, Nitric oxide; RA, right atrium; ROS, reactive oxygen species; RNS, reactive nitrogen species; SOD, superoxide dismutase; TTF, time until fatigue; TNF- $\alpha$, tumor necrosis factor-alpha.

* Corresponding author at: Department of Structural Biology, Federal University of Alfenas, Rua Gabriel Monteiro da Silva, 700, Alfenas 37130-000, Minas Gerais, Brazil.

E-mail address: romuonovaes@yahoo.com.br (R.D. Novaes). cardiomyopathy is the most serious clinical manifestation of Chagas disease and around 14,000 patients/year die due to congestive heart failure, complex dysrhythmias, heart blocks and thromboembolic events $[3,4]$. As a consequence of population migration from Central and South American endemic countries, Chagas disease has also become a serious health problem in non-endemic areas, especially in the United States of America and European countries [3,5,6].

Although the therapeutic management of Chagas disease is almost exclusively based on antiparasitic chemotherapy (i.e., benznidazole and nifurtimox) [1,3,7], non-pharmacological strategies such as exercise training therapy has emerged as a complementary approach for the treatment of Chagas cardiomyopathy $(\mathrm{ChC})[8,9,10]$. Even though scientific investigations in this area are scarce, there are recent studies indicating that chagasic patients exposed to a 12-week aerobic exercise training period presented significant increase in physical performance 
markers such as maximum oxygen consumption, peak of heart rate, chronotropic response, brain-derived neurotrophic factor serum levels, exercise tolerance, and health-related quality of life $[8,9,11]$. In mice, an 8 -week pre-infection treadmill training program proved to be a resistance factor in the development of acute infection caused by T. cruzi. This program was associated with reductions in total parasitemia and weight loss induced by the infection, a finding potentially related to immunomodulatory mechanisms triggered by exercise [12].

There is evidence that chronic exercise training of moderate intensity is associated with the installation of a complex cardioprotective phenotype [13]. Particularly in response to infections, physical training is able to modulate the immune system to a Th1 phenotype [14,15], essential to promote cell-mediated immunity and resistance against T. cruzi $[12,16]$. Furthermore, enhancing the endogenous antioxidant defenses is an important adaptation induced by exercise training that justifies the applicability of exercise therapy in the treatment of infectious diseases $[13,14,17]$. It is recognized that $\mathrm{ChC}$ has a worse prognosis than other non-inflammatory cardiomyopathies (i.e. ischemic, hypertensive, and idiopathic) [18], and the pivotal difference between these pathologies is an intense inflammatory process coupled with oxidative heart tissue damage. Therefore, it seems plausible that modulating the inflammatory process and oxidative cardiac status by exercise therapy could mitigate the progression and severity of $\mathrm{ChC}$. This study investigated the impact of a structured exercise training program on blood and heart parasitism, inflammation and oxidative cardiac damage, as well as the morphological and functional properties of cardiomyocytes in experimental ChC.

\section{Materials and methods}

\subsection{Animals and experimental design}

Fifty-six male Wistar rats (16-weeks-old) were randomized into four groups containing 14 animals each. Two of these groups were subjected to aerobic treadmill training (trained), and the others were maintained without exercise (sedentary). After the training period, animals of one trained and one control group (not trained) were infected with T. cruzi. The four groups were: sedentary not infected ( $\mathrm{SN}=14$ ), sedentary infected $(\mathrm{SI}=14)$, trained not infected $(\mathrm{TN}=14)$ and trained infected $(\mathrm{TI}=14)$. The animals were maintained in a controlled environment (temperature $22 \pm 2{ }^{\circ} \mathrm{C}$, humidity $60-70 \%$, and $12 / 12 \mathrm{~h}$ dark/light inverted cycles) with free access to chow and water. All experimental procedures were conducted in accordance with the National Institutes of Health guide for the care and use of Laboratory animals (NIH Publication No. 8023, revised 1978). The study was approved by the Animal Research Ethics Commission of the Federal University of Viçosa, Brazil (protocol 30/2009).

\subsection{Pre-infection treadmill running program}

All animals in the TN and TI groups were subjected to an incremental running training program on a motor-driven treadmill (Insight Instruments ${ }^{\circledR}$, Ribeirão Preto, Brazil), 5 days/week, for 9 weeks as previously described [19]. The parameters of velocity, inclination and time applied to running training were, respectively: Week 1 and 2) $17 \mathrm{~m} / \mathrm{min}, 0 \%$ grade for $15 \mathrm{~min}$. Exercise duration was increased $5 \mathrm{~min} /$ day until $60 \mathrm{~min} /$ session by the end of week 2. Weeks 3 and 4) $17 \mathrm{~m} / \mathrm{min}, 10 \%$ grade for $60 \mathrm{~min}$. Week 5) $17 \mathrm{~m} /$ min, $10 \%$ grade for $8 \mathrm{~min}$ at (warm-up), followed by $45 \mathrm{~min}$ at $20 \mathrm{~m} / \mathrm{min}$, and $5 \mathrm{~min}$ at $17 \mathrm{~m} / \mathrm{min}$ (warm-down). Weeks 6, 7, 8 and 9) $20 \mathrm{~m} / \mathrm{min}, 10 \%$ grade for $8 \mathrm{~min}$ (warm-up), followed by $45 \mathrm{~min}$ at $23 \mathrm{~m} / \mathrm{min}$, and $5 \mathrm{~min}$ at $18 \mathrm{~m} / \mathrm{min}$ (warm-down). Exercise training was initiated $24 \mathrm{~h}$ after determining the basal indexes of physical performance.

\subsection{Analysis of physical performance}

To evaluate the effect of exercise training and inactivity on the voluntary physical performance, all animals were subjected to a treadmill progressive running protocol [20]. This protocol was repeated three times on alternating days before and after the exercise program. For seven consecutive days, the animals were familiarized with the treadmill by running at $10 \mathrm{~m} / \mathrm{min}, 5 \%$ inclination for $5 \mathrm{~min} /$ day. After $48 \mathrm{~h}$, the analysis of physical performance was performed on three consecutive days at $5 \%$ inclination and initial speed at $10 \mathrm{~m} / \mathrm{min}$. The running speed was increased by $1 \mathrm{~m} / \mathrm{min}$ every 2 min until fatigue. The fatigue was established as the moment at which the animals were unable to maintain the running cadence and interrupted the race by over $10 \mathrm{~s}$. Traveled distance $(\mathrm{m})$, time until fatigue (min), and workload (W; $\mathrm{kg} \mathrm{m}$ ) were applied as performance markers. Workload was calculated as $\mathrm{W}=$ animal weight $(\mathrm{kg}) \times$ time until fatigue $(\mathrm{min}) \times$ running speed $(\mathrm{m} / \mathrm{min}) \times \operatorname{sine} \theta$ (treadmill inclination) [21]. All indexes were considered as the average values obtained from the three physical performance tests.

\subsection{Analysis of metabolic adaptation induced by exercise training}

Twenty-four hours after voluntary physical performance evaluation, the same treadmill running protocol was used to investigate metabolic adaptation induced by exercise training [20]. However, treadmill velocity was increased by $1 \mathrm{~m} / \mathrm{min}$ every $3 \mathrm{~min}$. During each speed transition, peripheral blood was collected to measure lactate levels (Accutrend Lactate ${ }^{\circledR}$, Roche, Basel, Switzerland). The transition point between the aerobic metabolism and anaerobic metabolism was determined by assessing the lactate threshold (LT), which is represented by the inflection point in which lactate blood levels exhibit exponential growth and lose linearity in accordance with increases in exercise intensity (time and velocity) [22].

\subsection{Infection and parasitemia}

Infected animals were inoculated with $T$. cruzi $(600,000$ trypomastigotes [Y strain]/100 g body weight, i.p.) obtained from the blood of infected mice [23]. The Y strain was selected due to high tropism by cardiac tissue and marked virulence [1]. The animals were inoculated $72 \mathrm{~h}$ after the last physical performance evaluation [12]. Confirmation of infection and parasitemia curves were determined using peripheral blood according Brener's protocol [24]. Nine weeks after inoculation, the animals were sacrificed under anesthesia with xylazine ( $2 \mathrm{mg} / \mathrm{kg}$, i.p.) and ketamine (10 $\mathrm{mg} / \mathrm{kg}$, i.p.).

\subsection{Biometry and histopathology}

The atria and ventricles of six animals in each group were dissected and weighed separately. The indexes of cardiac, atrial and ventricular hypertrophy were calculated by the ratios of heart, atrium and ventricle weight to body weight, respectively. Heart fragments were fixed for $48 \mathrm{~h}(10 \% \mathrm{w} / \mathrm{v}$ formaldehyde in $0.1 \mathrm{M}$ phosphate buffer, $\mathrm{pH} 7.2)$ [21]. The fragments of right atrium and left ventricle were embedded in paraffin, sectioned at 4- $\mu \mathrm{m}$ thickness and stained by hematoxylin-eosin. Histological sections were examined using a photomicroscope (Olympus BX-60 ${ }^{\circledR}$, Tóquio, Japan). Sixty histological fields ( $\times 400$ magnification) were randomly sampled and the myocardium (total area $=$ $1.41 \times 10^{6} \mu \mathrm{m}^{2}$ ) was analyzed [21].

Sections stained with H\&E was used to assess the presence and intensity of the inflammatory process in the infected animals compared to tissue cellularity observed in hearts from control animals. Tissue cellularity was evaluated in a test area of $3.4 \times 10^{3} \mu \mathrm{m}^{2}$ at a magnification of $\times 1000$ across 5 random microscopic fields of each animal in a total of $170 \times 10^{3} \mu \mathrm{m}^{2}$ of heart tissue for each group. Nuclei of cardiomyocytes were excluded from this count [21]. 
Table 1

Effect of exercise training on biometrical variables in control and T. cruzi infected rats.

\begin{tabular}{|c|c|c|c|c|}
\hline Parameter & $\mathrm{SN}$ & $\mathrm{TN}$ & SI & $\mathrm{TI}$ \\
\hline Initial BM (g) & $360.35 \pm 14.56^{\mathrm{a}}$ & $378.81 \pm 19.32^{\mathrm{a}}$ & $372.15 \pm 21.12^{\mathrm{a}}$ & $367.58 \pm 17.09^{a}$ \\
\hline Final BM (g) & $509.76 \pm 36.86^{a}$ & $505.61 \pm 8.65^{\mathrm{a}}$ & $497.90 \pm 17.31^{\mathrm{a}}$ & $495.32 \pm 9.15^{\mathrm{a}}$ \\
\hline $\mathrm{HM}(\mathrm{mg})$ & $2010.00 \pm 59.85^{\mathrm{a}}$ & $1978.03 \pm 53.40^{\mathrm{a}}$ & $2167.04 \pm 39.67^{b}$ & $2231.07 \pm 45.10^{\mathrm{b}}$ \\
\hline ATM (mg) & $588.71 \pm 49.74^{\mathrm{a}}$ & $579.02 \pm 28.30^{\mathrm{a}}$ & $592.01 \pm 79,61^{\mathrm{a}}$ & $623.21 \pm 26.70^{a}$ \\
\hline VEM (mg) & $1421.38 \pm 50.12^{\mathrm{a}}$ & $1399.01 \pm 48.90^{\mathrm{a}}$ & $1575.03 \pm 39.82^{\mathrm{b}}$ & $1607.86 \pm 32.20^{\mathrm{b}}$ \\
\hline HM:BM (mg/g) & $3.94 \pm 0.11^{\mathrm{a}}$ & $3.91 \pm 0.13^{\mathrm{a}}$ & $4.36 \pm 0.18^{\mathrm{b}}$ & $4.50 \pm 0.15^{\mathrm{b}}$ \\
\hline ATM:BM (mg/g) & $1.15 \pm 0.22^{\mathrm{a}}$ & $1.15 \pm 0.06^{\mathrm{a}}$ & $1.19 \pm 0.13^{\mathrm{a}}$ & $1.26 \pm 0.10^{\mathrm{a}}$ \\
\hline VEM:BM (mg/g) & $2.80 \pm 0.24^{\mathrm{a}}$ & $2.77 \pm 0.11^{\mathrm{a}}$ & $3.18 \pm 0.21^{\mathrm{b}}$ & $3.25 \pm 0.08^{\mathrm{b}}$ \\
\hline
\end{tabular}

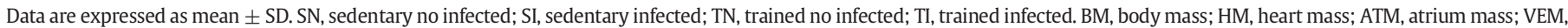
ventricle mass. ${ }^{\mathrm{a}, \mathrm{b}, \mathrm{c}}$ Different letters in rows indicate statistical difference between the groups $(\mathrm{p}<0.05)$.

\subsection{Scanning electron microscopy and spectrophotometry for collagen}

Myocardial fibrosis was evaluated by scanning electron microscopy. RA and LV samples not used for bright field microscopy were subjected to a $\mathrm{NaOH}$ maceration method for isolation of the collagen matrix [25]. The samples were immersed in a $10 \% \mathrm{NaOH}$ solution ( 6 days), rinsed in distilled water, immersed in $1 \%$ tannic $(4 \mathrm{~h})$, rinsed in distilled water overnight and post-fixed in $1 \%$ osmium tetroxide $(2 \mathrm{~h})$. The fragments were dehydrated in ethanol and to critical point (CPD030, Bal-tec, North Rhine-Westphalia, Germany), coated with gold, and observed using a scanning electron microscope (Leo 1430VP, Zeiss, Jena, Thuringia, Germany).

The collagen content was additionally quantified by a previously described micromethod [26]. For each group, twenty sections (8- $\mu \mathrm{m}$ thickness) stained with Fast Green and Sirius Red were used to measure total protein and collagen content in cardiac tissue using by spectrophotometry (Evolution-300, Thermo Scientific, Waltham, MA, USA). Using this method, the maximal absorbance to the Fast Green (605 nm) and Sirius Red (540 nm) dyes corresponds to the tissue level of non-collagenous proteins and collagen, respectively.

\subsection{Cardiomyocyte isolation and morphology}

At sacrifice, the hearts ( $\mathrm{n}=8$ /group) were rapidly removed and were flushed with a Hepes-Tyrode solution (10 glucose, 5 Hepes, 10 creatine, 20 taurine, $5.4 \mathrm{KCl}, 130 \mathrm{NaCl}, 0.4 \mathrm{NaH}_{2} \mathrm{PO}_{4}, 1.4 \mathrm{MgCl}_{2}$, and $0.75 \mathrm{CaCl}_{2}$ [mM, pH 7.4]). Cardiomyocytes were isolated by a collagenase-protease method using a Langendorff perfusion apparatus [27]. Briefly, the heart was perfused and digested with collagenase type II and the right atrium (RA) and left ventricle (LV) were separated. Ventricular and atrial cardiomyocytes were isolated by mechanical dispersion at $37{ }^{\circ} \mathrm{C}$ for $5 \mathrm{~min}$, filtered, centrifuged, and resuspended in Hepes-Tyrode solution. Only quiescent cardiomyocytes showing clear cross striations were studied. Measurements of cell length and width were obtained using a previously described edge detection system [27]. From these variables myocyte volume (V, pl) was calculated: Volume $(\mathrm{pl})=$ length $(\mu \mathrm{m}) \times$ width $(\mu \mathrm{m}) \times\left(7.59 \times 10^{-3} \mathrm{pl} / \mu \mathrm{m}^{2}\right)$. Sarcomere size was measured using an optical densitometry analysis of myocyte $\mathrm{Z}$ lines in an IonWizard A/Dconverter (Ionoptix, Milton, MA, USA).

\subsection{Biomechanics of isolated cardiomyocytes}

Isolated cardiomyocytes were placed in an experimental chamber mounted on the stage of an inverted-type phase contrast microscope (Eclipse-TS100, Nikon, Tokyo, Japan). The cells were perfused with Tyrode's solution (10 glucose, 10 HEPES, $5.4 \mathrm{KCl}, 1 \mathrm{MgCl}_{2}, 140 \mathrm{NaCl}$, and $\left.1.8 \mathrm{CaCl}_{2}\left[\mathrm{mM}, \mathrm{pH} 7.4, \sim 28^{\circ} \mathrm{C}\right]\right)$. Myocytes were stimulated with platinum electrodes at $20 \mathrm{~V}, 5 \mathrm{~ms}$ pulses, and $3 \mathrm{~Hz}$. Cells were examined in scanning mode on a PC monitor coupled with a video camera
Pre-training

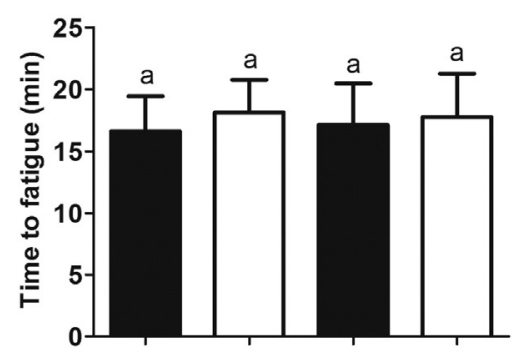

Post-training

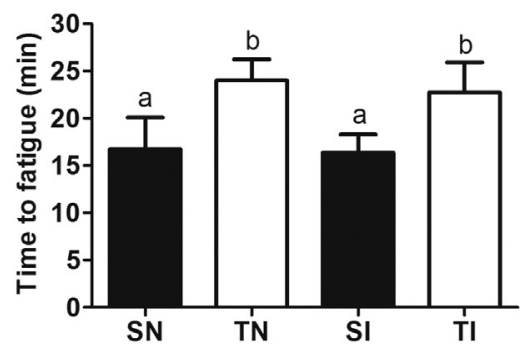

Pre-training

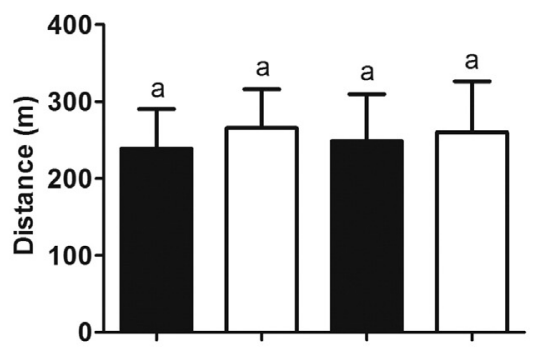

Post-training

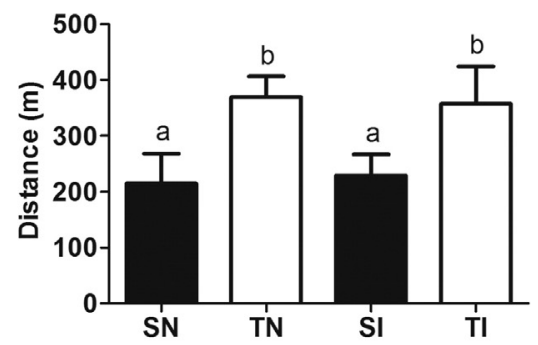

Pre-training

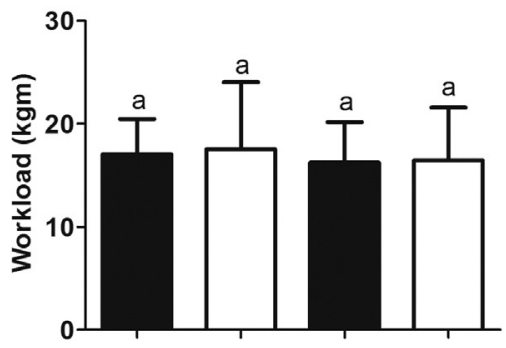

Post-training

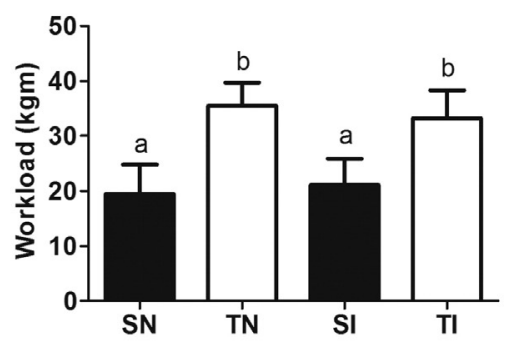

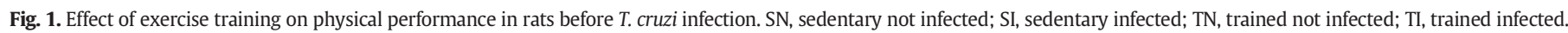
Data are expressed as mean \pm standard deviation. ${ }^{\mathrm{a}, \mathrm{b}, \mathrm{c}}$ Different letters in the columns denote statistical difference among the groups ( $\mathrm{p}<0.05$ ). 


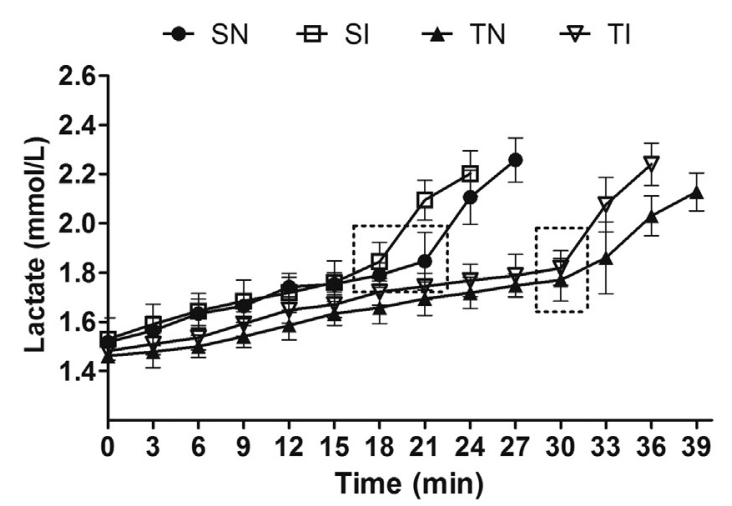

Fig. 2. Effect of exercise training on metabolic adaptations in rats before T. cruzi infection. SN, sedentary not infected; SI, sedentary infected; TN, trained not infected; TI, trained infected. Data are expressed as mean \pm standard deviation. The dotted boxes indicate the lactate threshold in both groups investigated.

(Ionoptix, CCD100V Myo-Cam, MA, USA). Cell shortening was measured using a real-time motion edge detection system (Ionoptix, MA, USA) [27]. From consecutive cardiomyocytes contractions (8 to 16), cell shortening, maximal rate of contraction and relaxation were calculated [28].

\subsection{Cytokines immunoassay}

The cytokine concentrations in serum and myocardium were measured by ELISA. The measurements in serum were performed for all animals $24 \mathrm{~h}$ after the last exercise session. Nine weeks after T. cruzi inoculation, RA and LV fragments were removed from 6 animals per group and used in this immunoassay. The cytokines TNF- $\alpha$, IFN- $\gamma$, IL- 6 and the chemokines CCL-2/MCP-1 and CX3CL1 were assayed following the manufacturer's instructions (Promega, Madison, WI, USA). The reaction was revealed using peroxidase-conjugated streptavidin (Vector Lab., CA, USA) and the substrate containing 3.3',5,5"tetramethylbenzidine (Promega, WI, USA). Optical densities were read by spectrophotometry at $450 \mathrm{~nm}$, and the levels of cytokines were calculated by extrapolating the optical densities obtained from a standard curve using recombinant cytokines.

\subsection{Oxidative/nitrosative stress markers}

The same RA and LV fragments used in the cytokine immunoassays were used for assessing oxidative and nitrosative markers. The status of lipid peroxidation was determined by analyze the tissue levels of malondialdehyde (MDA). In this analysis, $100 \mathrm{mg}$ of frozen heart was homogenized in PBS and incubated with thiobarbituric acid to determine the levels of thiobarbituric acid-reactive substances [29]. Protein oxidation was verified by the quantification of protein carbonyls in cardiac tissue using the 2.4-dinitrophenylhydrazine (DNPH) procedure [30]. Catalase (CAT) and Superoxide dismutase (SOD) were analyzed to estimate the antioxidant status of the cardiac tissue. CAT activity was evaluated by measuring the rate of decomposition of hydrogen peroxide $\left(\mathrm{H}_{2} \mathrm{O}_{2}\right)$, according to the protocol described by Aebi [31]. SOD activity was estimated by a method described by Sarban et al. [32], in which xanthine oxidase produce $\mathrm{H}_{2} \mathrm{O}_{2}$ reducing nitroblue tetrazolium. Nitric oxide (NO) was indirectly determined by the quantification of nitrite/nitrate levels in serum and cardiac tissue using the Griess method [33]. Total protein levels were measured using the Bradford method [34].

\subsection{Statistical analysis}

Data were reported as mean and standard deviation (mean \pm SD). Data distribution was verified by D'agostino-Pearson test. Parameters of exercise tolerance, biometry, biochemical and morphological data, were compared using analysis of variance ANOVA one-way followed by Tukey's post-hoc test. Parasitemia, cytokines and cell contractile function were compared using the Kruskal-Wallis test. A probability of $\mathrm{p}<0.05$ was considered statistically significant.

\section{Results}

The initial and final body mass of the animals was similar in all groups $(p>0.01)$. In both groups infected with $T$. cruzi there was a
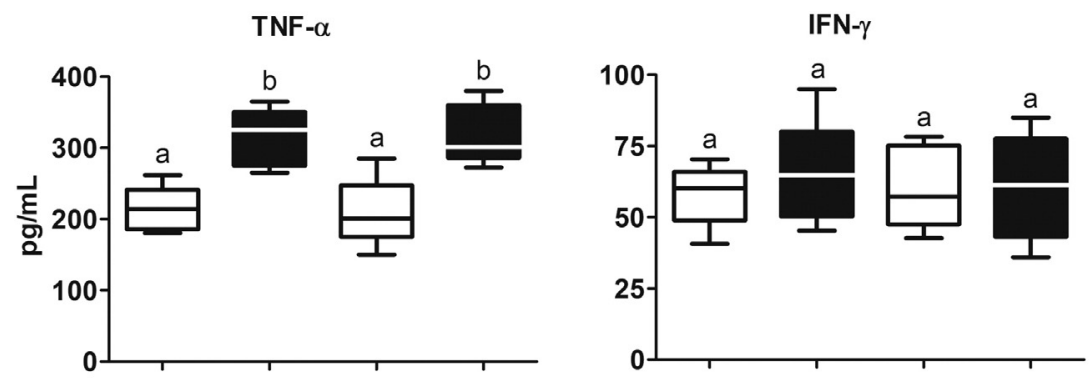

IL-6

\section{CCL-2/MCP-1}
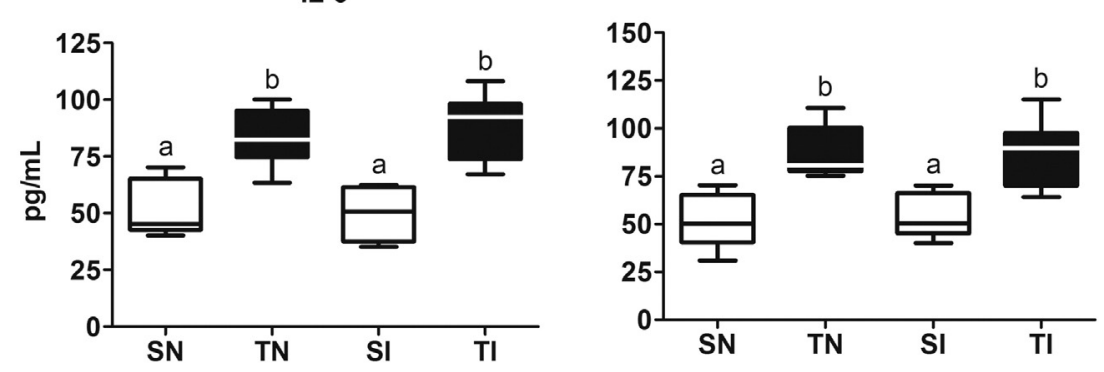

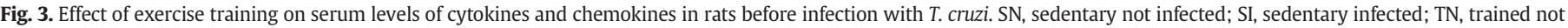

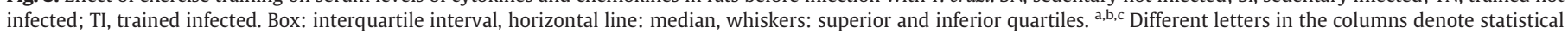
difference among the groups $(\mathrm{p}<0.05)$. 


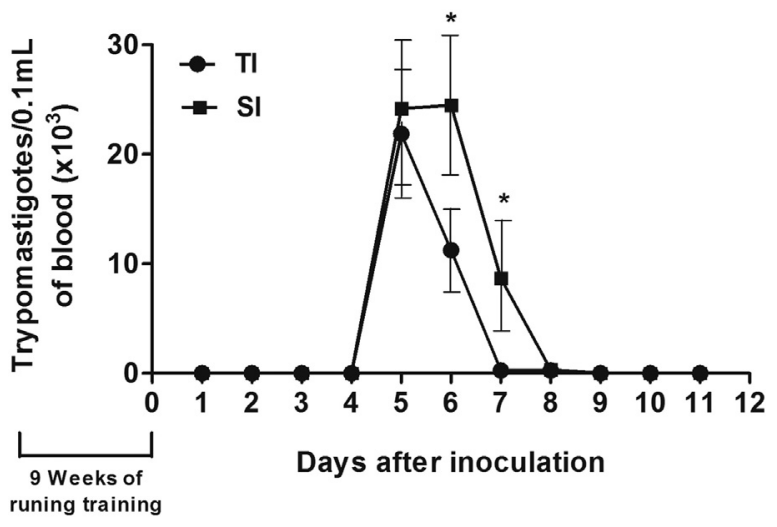

Fig. 4. Effect of exercise training on parasitemia in control and T. cruzi infected rats. SN, sedentary not infected; SI, sedentary infected; TN, trained not infected; TI, trained infected. Data are expressed as mean \pm standard deviation, ${ }^{*} \mathrm{p}<0.001$.

significant increase in the absolute and relative whole heart and ventricular mass compared to that of control animals $(p<0.01)$ (Table 1$)$.

As shown in Fig. 1, the initial level of physical performance obtained in the incremental running test was similar in all groups. Nine weeks after the treadmill running program, all variables of physical performance were significantly higher in both trained groups than those in sedentary animals $(\mathrm{p}<0.01)$.

The lactate threshold was reached late in trained animals compared to animals that remained sedentary during the experimental period (Fig. 2). At the beginning of the experiment, the lactate threshold occurred at similar time in both groups (data not shown).

Twenty-four hours after the last training session, exercised animals presented high levels of TNF- $\alpha$, IL-6 and CCL2/MCP-1 ( $<<0.01$ ), however they had similar values for IFN- $\gamma$ compared to control animals (p > 0.05) (Fig. 3).

After inoculation with T. cruzi, blood parasitism was detected on day five in all infected animals, which coincided with the peak of parasitemia in trained animals (Fig. 4). In the sedentary group, the peak of parasitemia was observed on the sixth day. Parasitemia was higher in sedentary (mean $14.42 \pm 6.10$; median 10.13 trypomastigotes $/ 0.1 \mathrm{~mL}$ of blood $\times 10^{3}$ ) compared to trained (mean $8.41 \pm 4.84$; median 6.00 trypomastigotes $/ 0.1 \mathrm{~mL}$ of blood $\times 10^{3}$ ) animals $(\mathrm{p}<0.05)$.

Nine weeks after exercise training, cardiac levels of TNF- $\alpha$ and CX3CL1 were higher in trained compared to sedentary uninfected animals (Fig. 5). All infected animals presented high levels of TNF- $\alpha$, IFN- $\gamma$, IL-6, CCL2/MCP-1, and CX3CL1 compared to those of the control sedentary animals $(\mathrm{p}<0.01)$. In trained and infected animals, the cardiac levels of TNF- $\alpha$, IFN- $\gamma$ and CX3CL1 were higher, CCL2/MCP-1 was lower $(p<0.01)$ and IL- 6 was similar compared to sedentary and infected animals $(\mathrm{p}>0.01)$.

Infected sedentary animals presented marked inflammatory infiltrate, cardiomyocyte hypotrophy (Fig. 6) and collagen content compared to the other groups (Table 2).

In all non-infected animals, thin collagen fibers were distributed in a well-organized, three-dimensional structure. Scanning electron microscopy revealed diffuse fibrosis with thick collagen fibers distributed in a disorganized pattern in all infected animals (Fig. 7). Tissue fibrosis was confirmed by spectrophotometric quantification of collagen in the myocardium (Table 2 ). All these variables showed lower values in infected and trained animals.

Myocardial levels of malondialdehyde and carbonyl proteins were similarly low in trained and sedentary uninfected control animals $(p>0.05)$ (Fig. 8). Infected animals presented significant protein oxidation compared to the other groups $(\mathrm{p}<0.05)$. Lipid and protein oxidation was attenuated by exercise in infected animals $(\mathrm{p}<0.05)$. Exercise training was also efficient in stimulating CAT $(\mathrm{p}<0.05)$ but not SOD activity $(p>0.05)$ in the myocardium. In addition, trained and infected animals presented increased SOD activity $(\mathrm{p}<0.05)$, but similar results for CAT $(\mathrm{p}<0.05)$ compared to sedentary and infected animals.

Both trained groups presented $\mathrm{NO}_{2}^{-} / \mathrm{NO}_{3}^{-}$serum levels significantly higher than sedentary animals $(\mathrm{p}<0.001)$. In uninfected animals, this adaptation was not maintained 9 weeks after stopping training $(\mathrm{p}>0.05)$. In infected animals, $\mathrm{NO}_{2}^{-} / \mathrm{NO}_{3}^{-}$levels in serum and myocardium were similar and significantly higher in trained and sedentary animals compared to those in both uninfected control groups ( $\mathrm{p}>0.05)$ (Fig. 9).
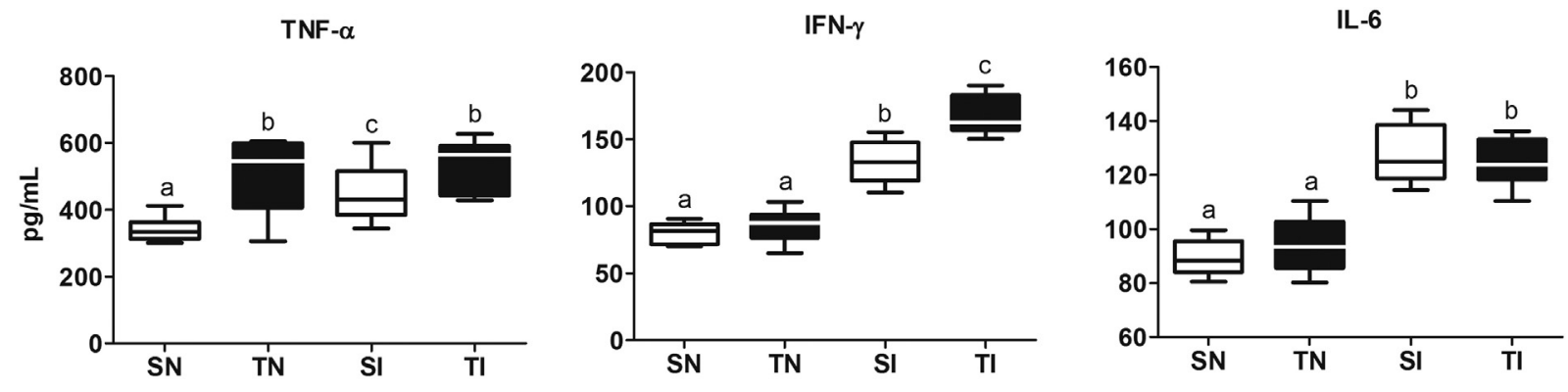

CCL-2/MCP-1

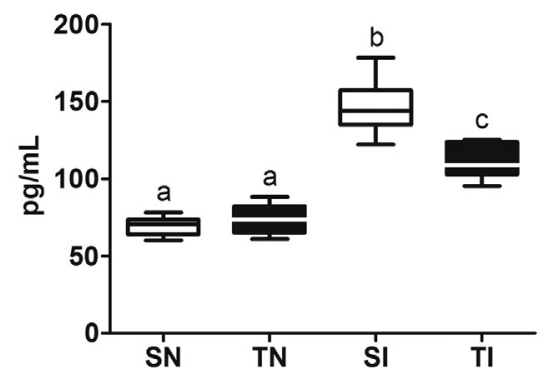

CX3CL1

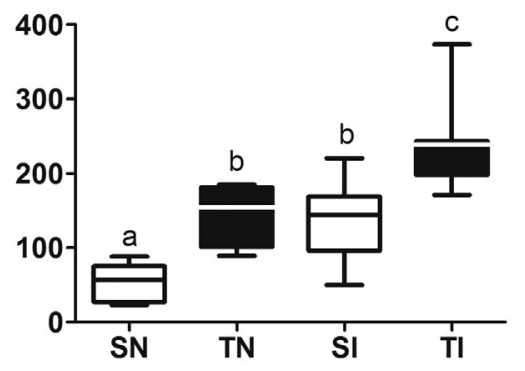

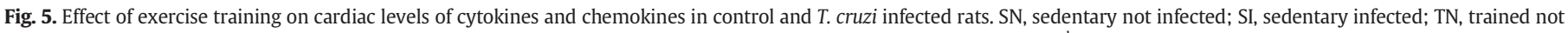

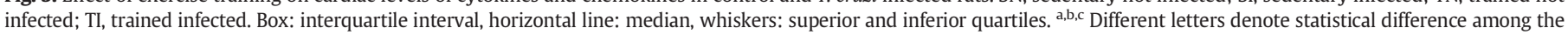
groups $(\mathrm{p}<0.05)$. 

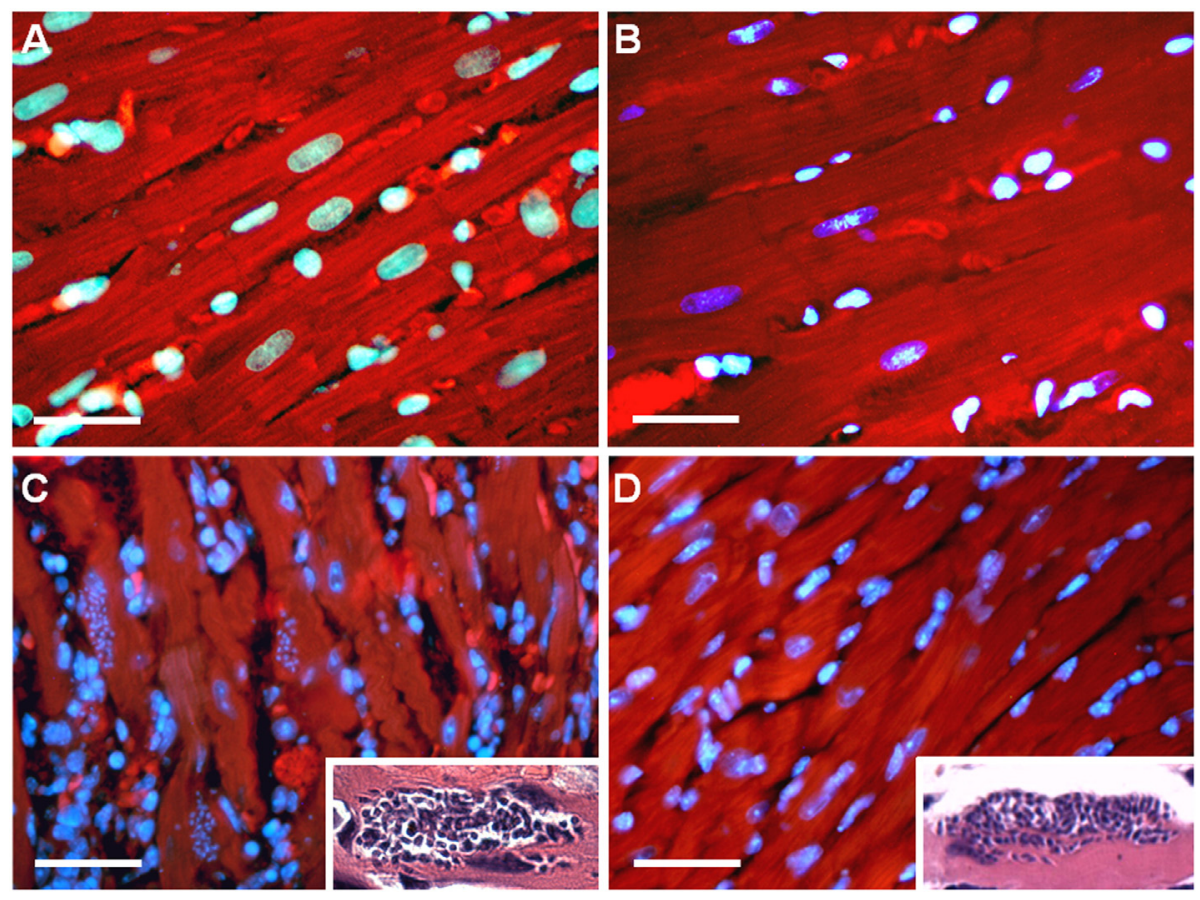

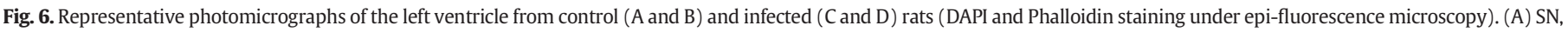

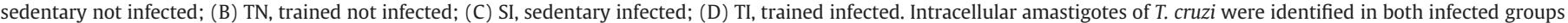
(highlighted in panels $\mathrm{C}$ and $\mathrm{D}, \mathrm{H} \& \mathrm{E}$ staining).

The morphological properties of isolated atrial and ventricular cardiomyocytes are shown in Table 3. The lower width and cellular volume reinforces the evidence of cardiomyocyte hypotrophy in both infected groups. Sedentary, but not trained and infected animals, also presented lower sarcomere length compared to the other groups.

The biomechanical characteristics of isolated atrial and ventricular cardiomyocytes are shown in Fig. 10. In uninfected and trained animals, it was observed a greater contraction velocity in atrial and ventricular cardiomyocytes and amplitude of shortening in ventricular cardiomyocytes $(\mathrm{p}<0.05)$. Sedentary and infected animals presented reduced cell shortening, contraction and relaxation velocity compared to control animals $(\mathrm{p}<0.05)$. In infected and trained animals, all parameters investigated were higher compared to the animals that remain sedentary $(\mathrm{p}<0.05)$, except relaxation velocity in atrial cardiomyocytes $(\mathrm{p}>0.05)$.

\section{Discussion}

In the present study, by modulating the cardiac inflammatory process and oxidative status, exercise training appears to be a potential effective complementary, non-pharmacological strategy to change the pathological repercussions of ChC. Our results suggested that that exercise training may induce beneficial adaptations to the host, which seems to be related to the increased production of Th1 cytokines (i.e. IFN- $\gamma$ and
TNF- $\alpha$ ), reduction in parasitemia levels, cardiac parasitism, inflammation, fibrosis and cell atrophy. Concurrently, trained animals presented increased activities of antioxidant enzymes, reduced cardiac oxidative damage and cardiomyocyte contractile dysfunction in infected rats.

As expected, both trained groups presented better physical performance and metabolic adaptation than sedentary animals, which was accompanied by increased circulating levels of IL- 6 and TNF- $\alpha$ and lower parasitemia. Previous studies have recognized the immunomodulatory effects of physical training by demonstrating that chronic exercise enhances leukocyte function indexes, including the "oxidative burst" of neutrophils and monocytes, TCD4 + /TCD8 + lymphocyte ratio and proliferation, antibody synthesis, and cytotoxic activity of NK cells [15,35]. It has been shown that in response to infections physical training is able to stimulate the production of TNF- $\alpha$, IFN- $\gamma$, IL-12, CCL2/MCP-1, CCL3/MIP- $1 \alpha$ and CCL4/MIP-1 $\beta$, molecules involved in the polarization to a Th1 immune response pattern $[14,15]$, which is essential to promote cell-mediated immunity against $T$. cruzi $[12,16]$. Thus, the reduced parasitemia observed here can be potentially related to high expression of Th1 cytokines (especially IFN- $\gamma$ and TNF- $\alpha$ ), an opposite effect when Th2 cytokines (i.e., IL-10, IL- 4 and TGF- $\beta$ ) are predominant, since these molecules increase the susceptibility to infection [16,36]. However, it should be considered that the expression of Th2 response could modulate the tissue damage caused by the immune response directed against the parasite [16].

Table 2

Effect of preinfection treadmill training on collagen content and myocardial cellularity in control and T. cruzi infected rats.

\begin{tabular}{|c|c|c|c|c|}
\hline Variables & SN & $\mathrm{TN}$ & SI & $\mathrm{TI}$ \\
\hline \multicolumn{5}{|l|}{ Right atrium } \\
\hline Collagen ( $\mu \mathrm{g} / \mathrm{mg}$ protein) & $17.52 \pm 1.40^{\mathrm{a}}$ & $16.77 \pm 1.07^{\mathrm{a}}$ & $28.60 \pm 1.55^{\mathrm{b}}$ & $23.71 \pm 1.13^{c}$ \\
\hline MC $\left(\right.$ cells $\left./ 170 \times 10^{3} \mu \mathrm{m}^{2}\right)$ & $101.15 \pm 15.65^{\mathrm{a}}$ & $117.90 \pm 18.95^{\mathrm{a}}$ & $356.40 \pm 14.01^{\mathrm{b}}$ & $179.60 \pm 16.62^{c}$ \\
\hline \multicolumn{5}{|l|}{ Left ventricle } \\
\hline Collagen ( $\mu \mathrm{g} / \mathrm{mg}$ protein) & $20.59 \pm 1.33^{\mathrm{a}}$ & $18.86 \pm 1.13^{\mathrm{a}}$ & $30.93 \pm 1.85^{\mathrm{b}}$ & $25.29 \pm 1.17^{c}$ \\
\hline $\mathrm{MC}\left(\right.$ cells $\left./ 170 \times 10^{3} \mu \mathrm{m}^{2}\right)$ & $94.10 \pm 19.49^{\mathrm{a}}$ & $115.25 \pm 17.03^{a}$ & $625.60 \pm 84.57^{\mathrm{b}}$ & $403.00 \pm 71.65^{c}$ \\
\hline
\end{tabular}

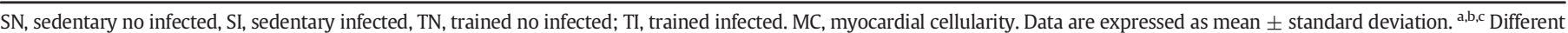
letters in rows indicate statistical differences between the groups for the same cardiac segment $(\mathrm{p}<0.05)$. 

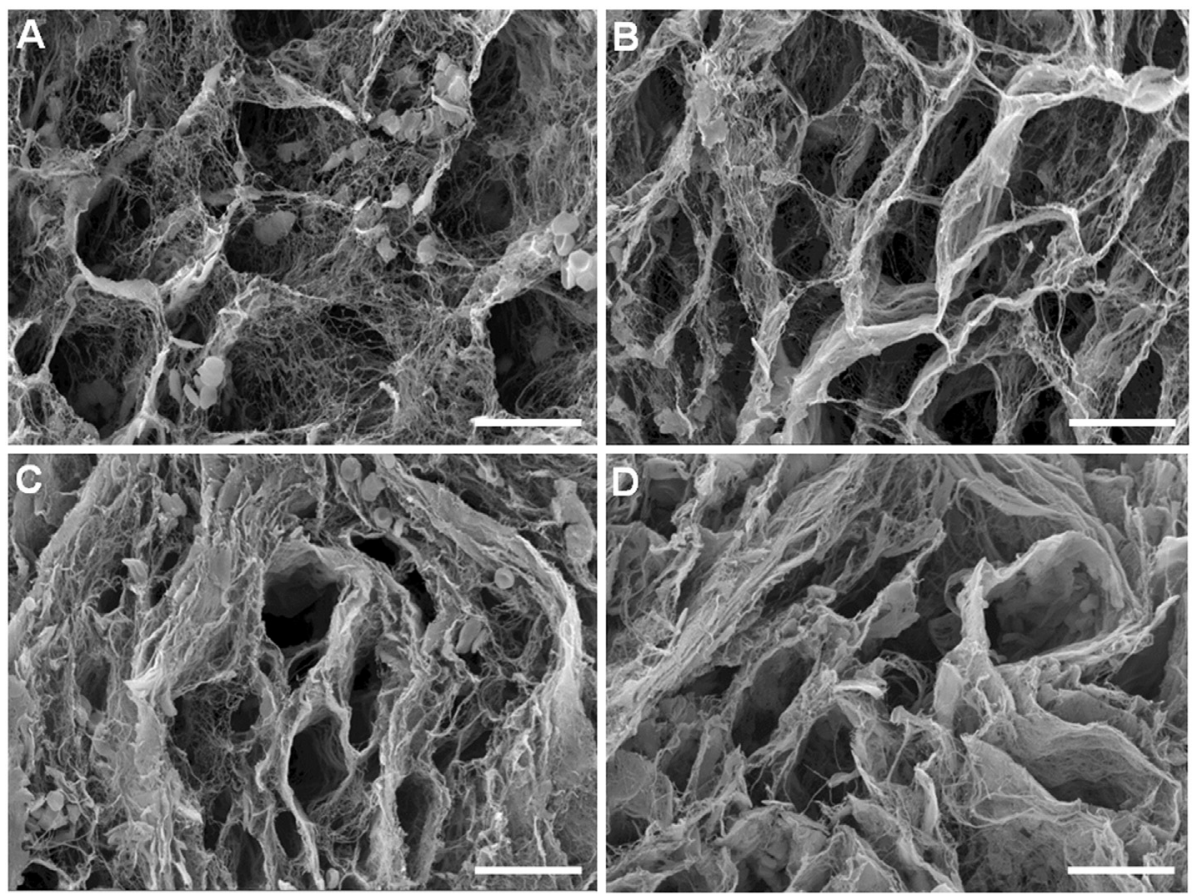

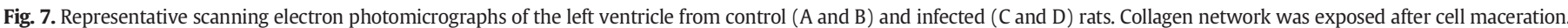
(A) SN, sedentary not infected; (B) TN, trained not infected; (C) SI, sedentary infected; (D) TI, trained infected (bars $=15 \mu \mathrm{m}$ ).

In addition to probably modifying the plasma levels of cytokines, exercise training seems to reduce cardiac parasitism, inflammation and fibrosis. In Chagas disease, the establishment of a pro-inflammatory response is critical in controlling the intense parasitism of the acute phase, however, this response often leads to the installation of a fibrosing cardiomyopathy in the chronic phase [4,37]. In humans with chronic heart failure, physical training was able to reduce CCL2 serum levels, an event associated with reduced macrophage recruitment, inflammation and heart failure progression [38]. A similar finding was observed in the present study, in which infected and trained animals presented lower CCL2 levels and tissue cellularity compared to infected and sedentary animals. In individuals with coronary artery disease, physical training was effective in stimulating an anti-inflammatory cardioprotective phenotype, reducing IL-1, IL-6, and IFN- $\gamma$ and increasing IL-10 circulating levels, a potent anti-inflammatory cytokine [39]. In humans with chronic heart failure, physical training also reduced TNF- $\alpha$ and IL-6 plasma levels [38], which are cytokines that directly modulate tissue inflammation and cardiac function, in addition to affecting the production of reactive oxygen (ROS) and nitrogen (RNS)-derived species that are involved in the pathogenesis of $\mathrm{ChC}[35,38]$.

As expected, NO serum levels were increased in trained animals, a mechanism admittedly associated with an increased tissue expression
A

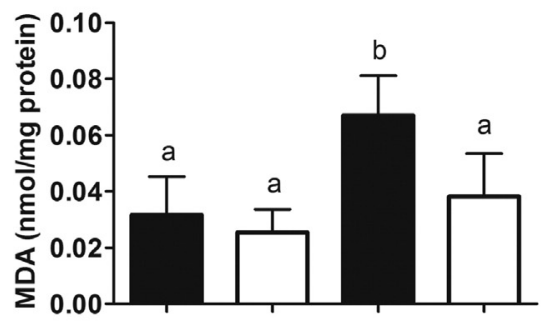

B

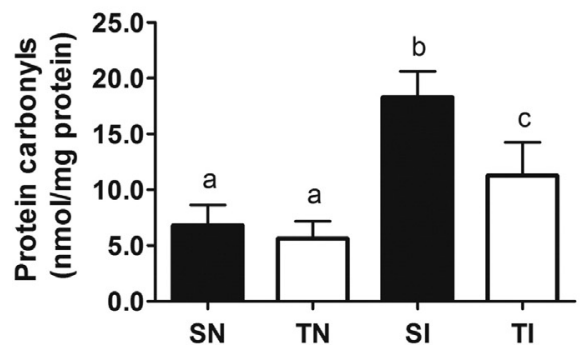

\section{C}

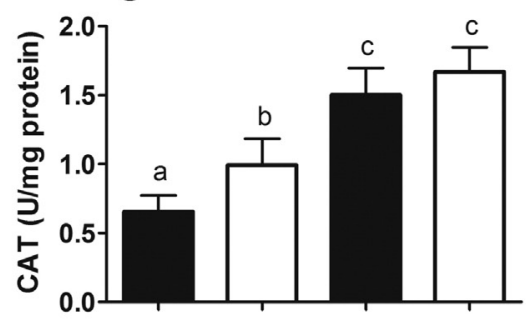

D

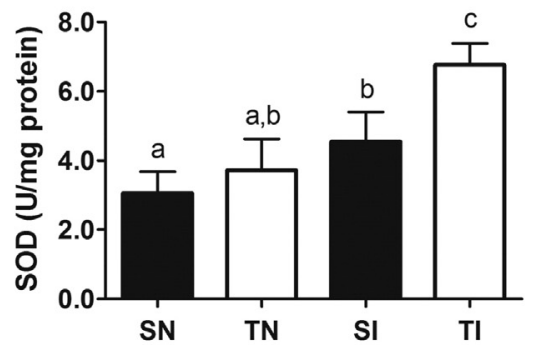

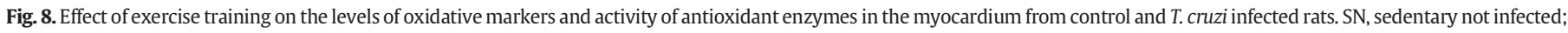

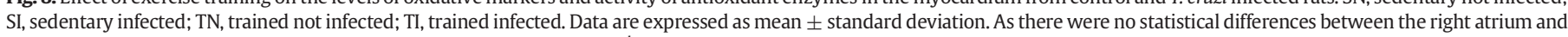
left ventricle, the data represent the average for both cardiac segments. ${ }^{\text {a,b,c }}$ Different letters in the columns denotes statistical difference between the groups ( $p<0.001$ ). 

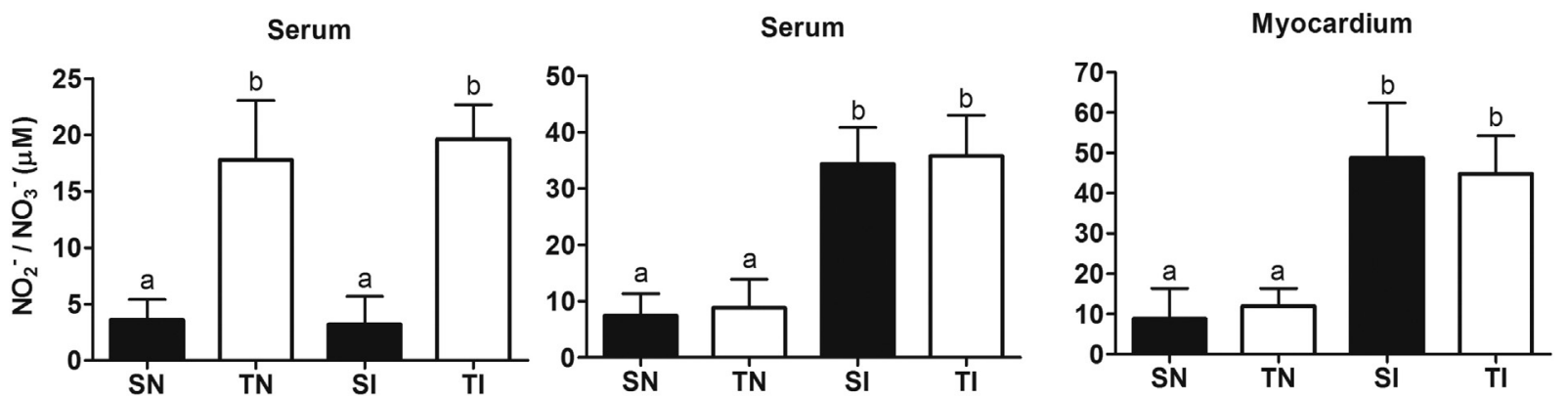

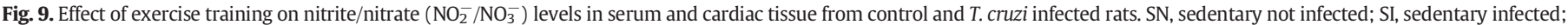

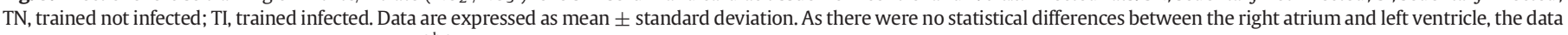
represent the average for both cardiac segments. ${ }^{a, b, c}$ Different letters in the columns denotes statistical difference between the groups for the same cardiac segment ( $p<0.001$ ).

of inducible and endothelial nitric oxide synthase (iNOS and eNOS) triggered by exercise training $[13,35,40]$. Although, this adaptation has been transitory, the host ability to produce NO in response to T. cruzi infection was not affected by exercise training. In addition, significant reactive tissue damage (i.e., MDA and protein carbonyls) was observed in infected animals, which was attenuated by exercise training. In humans [17] and animals [41,42], the installation of a pro-oxidant status of progressive intensity over $T$. cruzi infection has been described, in which the endogenous antioxidant reservation is not sufficient to counteract the high ROS and RNS production and limit tissue damage [41-45]. It has been demonstrated that the recruitment of inflammatory cells to cardiac tissue activates a respiratory burst that culminates in the intensive formation of ROS such as superoxide anions $\left(\mathrm{O}_{2}^{-}\right)$, hydroxyl radicals $\left(\mathrm{OH}^{-}\right)$and hydrogen peroxide $\left(\mathrm{H}_{2} \mathrm{O}_{2}\right)[42,43]$. These reactive species are also produced by cardiomyocytes, an event that not only represents a host defense mechanism against the parasite, but a mitochondrial dysfunction that occurs during cell parasitism. Thus, ROS/RNS production by cardiomyocytes seems to be a susceptibility factor for myocardial damage, cell death, increased inflammation and myocardial dysfunction in ChC [42-45], which can be mitigated by antioxidant strategies [41].

In the present study, the increased activity of antioxidant enzymes seems to constitute a remarkable cardiac adaptation induced by exercise training in infected animals. Operating predominantly on skeletal and cardiac muscle, it is recognized that chronic exercise can increase the expression and activity of antioxidant enzymes such as superoxide dismutase, glutathione peroxidase, glutathione-S-transferase and catalase, enhancing tissue efficiency in neutralize the excess of ROS/RNS $[13,46]$. Although in cardiomyopathies with other etiologies there is a compensatory reaction of antioxidant enzymes to neutralize the excess of reactive species, this mechanism is limited in Chagas disease and seems to be insufficient to prevent reactive myocardial damage and inflammatory cardiomyopathy progression $[42,43]$. In humans, the extent to which ChC worsens, there is a gradual reduction in GPX, SOD and GST activities in blood elements [47]. Due to a reduction in expression of these enzymes in more advanced stages of heart failure, endogenous antioxidant insufficiency seems to contribute to the progression of ChC $[44,47]$. Thus, by enhancing the enzymatic antioxidant defenses, physical training could be potentially beneficial in mitigating oxidative tissue damage and the severity of ChC.

It is known that cytokines and chemokines can change the redox balance in multiple organs $[42,48]$. There is evidence that T. cruzi exposure increases the circulating levels of TNF- $\alpha$, IL-1 and IL-6, which participate in parasite control by stimulating ROS/RNS synthesis $[42,43]$. Our results corroborated this association between cytokines and ROS/ RNS in infected sedentary animals, which presented high levels of TNF- $\alpha$ and IL- 6 together with increased lipid and protein oxidative damage. In cardiomyocytes infected with $T$. cruzi, the production of reactive species can be increased by TNF- $\alpha$, IFN- $\gamma$ and IL- $1 \beta$, which does not occur when non-infected cardiomyocytes are treated with these molecules $[42,43]$. A key role has been reported for TNF- $\alpha$ and IFN- $\gamma$ in inducing NO synthesis in animals infected with T. cruzi, a molecule directly involved in host resistance to infection and in the control of parasitemia and cell parasitism [39,47]. In humans, TNF- $\alpha$ and NO levels were inversely correlated with the levels of antioxidant enzymes SOD and GPx, and directly correlated with the severity of ChC [47], a proposition apparently applicable to sedentary but not trained animals.

Currently, investigations on the intrinsic contractile properties of cardiac myocytes in Chagas disease are scarce, constituting a neglected issue. In this study, T. cruzi infection markedly impaired cardiomyocyte contractility, which seems to be partially restored by exercise training. Our results support the evidence of a potential negative influence of reactive stress on cardiomyocyte contractility. Studies conducted by our

Table 3

Effect of preinfection treadmill training on morphological parameters of isolated cardiomyocytes from control and T. cruzi infected rats.

\begin{tabular}{|c|c|c|c|c|}
\hline Cell dimensions & SN & TN & SI & $\mathrm{TI}$ \\
\hline \multicolumn{5}{|l|}{ Right atrium } \\
\hline Length $(\mu \mathrm{m})$ & $183.81 \pm 6.64^{\mathrm{a}}$ & $181.72 \pm 5.84^{\mathrm{a}}$ & $180.91 \pm 10.46^{\mathrm{a}}$ & $187.96 \pm 8.53^{\mathrm{a}}$ \\
\hline Width $(\mu \mathrm{m})$ & $21.78 \pm 1.08^{\mathrm{a}}$ & $22.16 \pm 1.31^{\mathrm{a}}$ & $17.85 \pm 1.24^{\mathrm{b}}$ & $18.24 \pm 1.18^{\mathrm{b}}$ \\
\hline Volume (pl) & $30.42 \pm 1.77^{\mathrm{a}}$ & $30.59 \pm 1.81^{\mathrm{a}}$ & $24.60 \pm 1.57^{b}$ & $24.65 \pm 1.35^{b}$ \\
\hline $\mathrm{SL}(\mu \mathrm{m})$ & $1.94 \pm 0.07^{\mathrm{a}}$ & $1.93 \pm 0.08^{a}$ & $1.63 \pm 0.08^{\mathrm{b}}$ & $1.91 \pm 0.10^{\mathrm{a}}$ \\
\hline \multicolumn{5}{|l|}{ Left ventricle } \\
\hline Length $(\mu \mathrm{m})$ & $185.28 \pm 4.84^{\mathrm{a}}$ & $186.84 \pm 6.94^{\mathrm{a}}$ & $185.89 \pm 4.82^{\mathrm{a}}$ & $184.06 \pm 7.49^{\mathrm{a}}$ \\
\hline Width $(\mu \mathrm{m})$ & $20.32 \pm 1.16^{\mathrm{a}}$ & $21.54 \pm 1.40^{\mathrm{a}}$ & $16.18 \pm 1.37^{\mathrm{b}}$ & $17.83 \pm 1.05^{\mathrm{b}}$ \\
\hline Volume (pl) & $28.59 \pm 2.04^{\mathrm{a}, \mathrm{c}}$ & $30.46 \pm 2.35^{\mathrm{a}}$ & $21.15 \pm 1.81^{\mathrm{b}}$ & $26.45 \pm 1.29^{c}$ \\
\hline $\mathrm{SL}(\mu \mathrm{m})$ & $1.93 \pm 0.04^{\mathrm{a}}$ & $1.91 \pm 0.06^{\mathrm{a}}$ & $1.68 \pm 0.10^{\mathrm{b}}$ & $1.92 \pm 0.09^{\mathrm{a}}$ \\
\hline
\end{tabular}

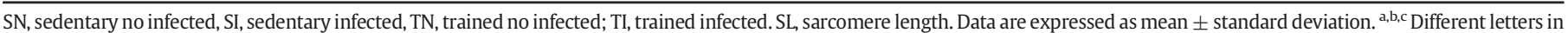
rows indicate statistical difference between the groups for the same cardiac segment $(\mathrm{p}<0.05)$. 
RA

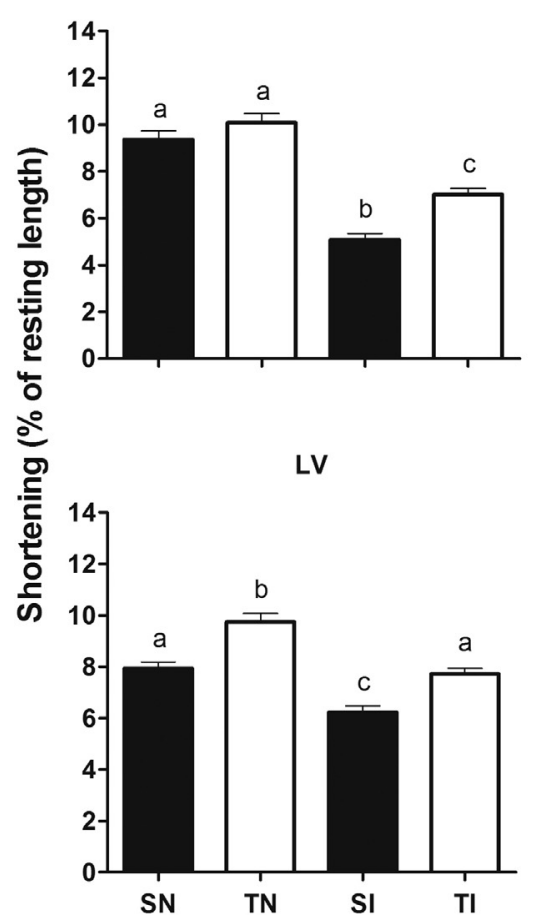

RA

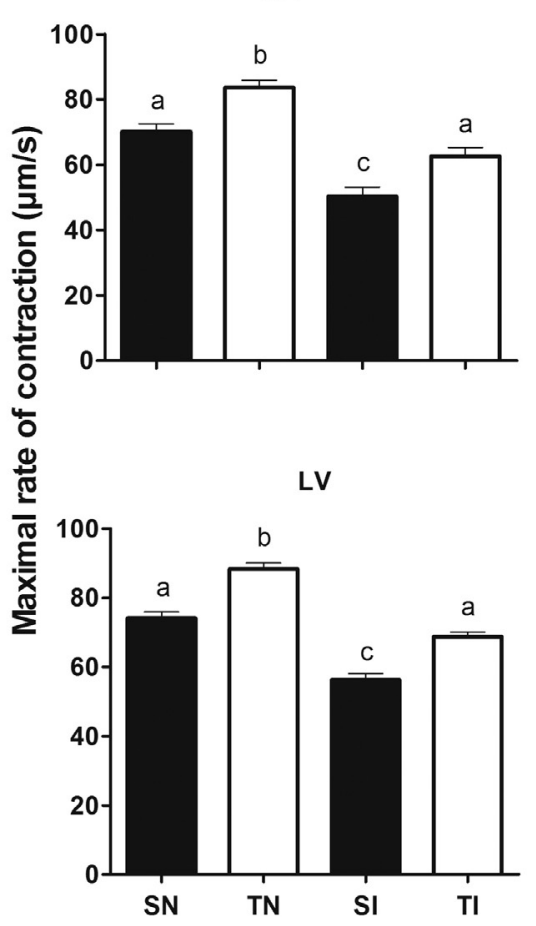

RA

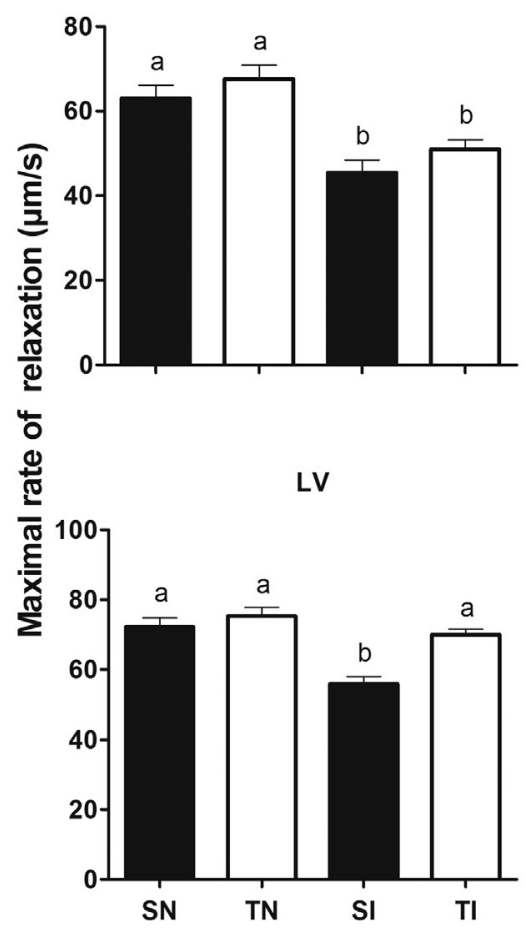

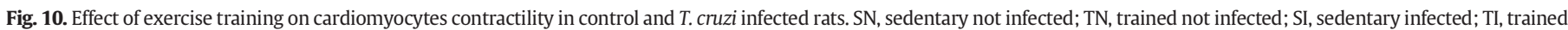

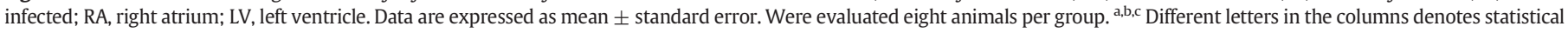
difference between the groups for the same cardiac segment $(p<0.001)$.

research group revealed for the first time that $T$. cruzi infection changes the intrinsic mechanical properties of cardiomyocytes, reducing the amplitude and cell contraction velocity $[21,23,28]$. Apparently, these changes are unstable and are influenced by the profile of cytokine expression, which varies with infection [28]. Thus, high IFN- $\gamma$, TNF- $\alpha$ and MCP-1/CCL2 serum levels were correlated with poor contractile responses in cardiomyocytes from $T$. cruzi infected mice, indicating an important role of these molecules in modulating cell biomechanics in experimental Chagas disease [28]. It has been proposed that contractility dysfunctions in ChC may also be associated with pro-oxidant events that generate cumulative damage to myocardium biomolecules, which can determine morphofunctional changes in cardiomyocytes and eventually cell death [23]. In fact, the morphological properties of cardiomyocytes (i.e., width, volume and sarcomere length) were impaired in infected and sedentary animals, which seems to be partially attenuated by physical training. As cell morphology is directly associated with cardiomyocyte biomechanics, it is possible to assume that by restricting cell atrophy and geometric disorders in sarcomeric unities, exercise training can improve cardiomyocyte contractility, counteracting the typical cardiac catabolic pattern observed in T. cruzi infection. Our research group also found that reactive tissue damage can be associated with profound cardiac pathological remodeling, especially stromal expansion and microvascular damage, events potentially associated with cardiomyocyte biomechanical dysfunction in T. cruzi infection [23]. Thus, by enhancing the antioxidant defenses and limiting oxidative tissue damage, exercise training could attenuate the installation of cardiac morphological abnormalities, especially the remarkable myocardium fibrosis, cell atrophy, and cardiomyocytolysis, which together with severe inflammation represent peculiar pathological aspects in $\mathrm{ChC}[5,37]$.

\section{Conclusion}

Taken together, the results suggested that pre-infection exercise training could be a relevant complementary non-pharmacological strategy to change the pathological repercussions of ChC. By modulating the immune response and enhancing the efficiency of endogenous antioxidant mechanisms, exercise training seems to improve the host resistance to infection. This is probably associated with multiple factors such as reduction of parasitemia, parasitism, cardiac inflammation, fibrosis, and reactive tissue damage, with positive repercussions to cardiomyocyte contractile function in rats.

\section{Conflict of interest statements}

There are no conflicts of interest. All authors contributed to data collection and analysis, article preparation and have approved the final manuscript.

\section{Acknowledgments}

This work was supported by the Brazilian funding agencies Conselho Nacional de Desenvolvimento Científico e Tecnológico (CNPq) (454901/ 2014-3) and Fundação de Amparo à Pesquisa do Estado de Minas Gerais (FAPEMIG) (APQ-02309-14). The authors André Talvani and Antônio J. Natali have research fellowships from Conselho Nacional de Desenvolvimento Científico e Tecnológico (CNP-q), Brazil. The authors thank the "Núcleo de Microscopia and Microanálise - NMM" of the Federal University of Viçosa by assistance in scanning electron microscopy.

\section{References}

[1] M.T. Bahia, I.M. de Andrade, T.A. Martins, et al., Fexinidazole: a potential new drug candidate for Chagas disease, PLoS Negl. Trop. Dis. 6 (2012), e1870.

[2] M.C. Nunes, W. Dones, C.A. Morillo, J.J. Encina, A.L. Ribeiro, Council on Chagas disease of the Interamerican Society of Cardiology, Chagas disease: an overview of clinical and epidemiological aspects. J. Am. Coll. Cardiol. 62 (2013) 767-776.

[3] WHO, World Health Organization, Chagas disease American trypanosomiasis, Fact sheet 340 (2015).

[4] A. Rassi-Jr, A. Rassi, J.A. Marin-Neto, Chagas disease, Lancet 375 (2010) 1388-1402. 
[5] R.A. Guerri-Guttemberg, D.R. Grana, G. Ambrosio, J. Milei, Chagas cardiomyopathy: Europe is not spared! Eur. Heart J. 29 (2008) 2587-2591.

[6] P.J. Hotez, E. Dumonteil, L. Woc-Colburn, et al., Chagas disease: "the new HIV/AIDS of the Americas", PLoS Negl. Trop. Dis. 6 (2012), e1498.

[7] J.R. Coura, Present situation and new strategies for Chagas disease chemotherapy: a proposal, Mem. Inst. Oswaldo Cruz 104 (2009) 549-554.

[8] M.M. Lima, M.O. Rocha, M.C. Nunes, et al., A randomized trial of the effects of exercise training in Chagas cardiomyopathy, Eur. J. Heart Fail. 12 (2010) 866-873.

[9] M.M. Lima, M.C. Nunes, B. Nascimento, et al., Improvement of the functional capacity is associated with BDNF and autonomic modulation in Chagas disease, Int. J. Cardiol. 167 (2013) 2363-2366.

[10] B.R. Nascimento, M.M. Lima, Mdo.C. Nunes, et al., Effects of exercise training on heart rate variability in Chagas heart disease, Arq. Bras. Cardiol. 103 (2014) 201-208.

[11] M.M. Lima, M.C. Nunes, M.O. Rocha, F.R. Beloti, M.C. Alencar, A.L. Ribeiro, Left ventricular diastolic function and exercise capacity in patients with Chagas cardiomyopathy, Echocardiography 27 (2010) 519-524.

[12] C. Schebeleski-Soares, R.C. Occhi-Soares, S.M. Franzói-de-Moraes, et al., Preinfection aerobic treadmill training improves resistance against Trypanosoma cruzi infection in mice, Appl. Physiol. Nutr. Metab. 34 (2009) 659-665.

[13] S.K. Powers, S.L. Lennon, J. Quindry, J.L. Mehta, Exercise and cardioprotection, Curr. Opin. Cardiol. 17 (2002) 495-502.

[14] T. Lowder, D.A. Padgett, J.A. Woods, Moderate exercise protects mice from death due to influenza virus, Brain Behav. Immun. 19 (2005) 377-380.

[15] C. Malm, Exercise immunology: the current state of man and mouse, Sports Med. 34 (2004) 555-566.

[16] M.M. Teixeira, R.T. Gazzinelli, J.S. Silva, Chemokines, inflammation and Trypanosome cruzi infection, Trends Parasitol. 18 (2002) 262-265.

[17] L.B. Maçao, F.D. Wilhelm, R.C. Pedrosa, et al., Antioxidant therapy attenuates oxidative stress in chronic cardiopathy associated with Chagas' disease, Int. J. Cardiol. 123 (2007) 43-49.

[18] C.P. Silva, C.H. Del Carlo, M.T. Oliveira Junior, Why do patients with chagasic cardiomyopathy have worse outcomes than those with non-chagasic cardiomyopathy? Arq. Bras. Cardiol. 91 (2008) 358-362.

[19] W. Lunz, M.C.G. Peluzio, C.M.G.C. Dias, A.P.B. Moreira, A.J. Natali, Long-term aerobic swimming training impairs the development of colon cancer in rats treated with 1.2-dimethyl-hydrazine, Braz. J. Med. Biol. Res. 41 (2008) 1000-1004.

[20] L.G. Koch, S.L. Britton, Artificial selection for intrinsic aerobic endurance running capacity in rats, Physiol. Genomics 5 (2001) 45-52.

[21] R.D. Novaes, A.R. Penitente, R.V. Gonçalves, Effects of Trypanosoma cruzi infection on myocardial morphology, single cardiomyocyte contractile function and exercise tolerance in rats, Int. J. Exp. Pathol. 92 (2011) 299-307.

[22] APS, American Physiological Society, Resource Book for the Design of Animal Exercise Protocols, 2006.

[23] R.D. Novaes, A.R. Penitente, R.V. Gonçalves, et al., Trypanosoma cruzi infection induces morphological reorganization of the myocardium parenchyma and stroma, and modifies the mechanical properties of atrial and ventricular cardiomyocytes in rats, Cardiovasc. Pathol. 22 (2013) 270-279.

[24] Z. Brener, Therapeutic activity and criterion of cure on mice experimentally infected with Trypanosoma cruzi, Rev. Inst. Med. Trop. São Paulo 4 (1962) 389-396.

[25] M.A. Rossi, M.A. Abreu, L.B. Santoro, Images in cardiovascular medicine. Connective tissue skeleton of the human heart: a demonstration by cell-maceration scanning electron microscope method, Circulation 97 (1998) 934-935.

[26] A. López-De León, M. Rojkind, A simple micromethod for collagen and total protein determination in formalin-fixed paraffin-embedded sections, Histochem. Cytochem. 33 (1985) 737-743.

[27] A.J. Natali, LA. Wilson, M. Peckham, D.L. Turner, S.M. Harrison, E. White, Different regional effects of voluntary exercise on the mechanical and electrical properties of rat ventricular myocytes, J. Physiol. 541 (2002) 863-875.
[28] D. Roman-Campos, H.L.L. Duarte, P.A. Sales-Jr, et al., Changes in cellular contractility and cytokines profile during Trypanosoma cruzi infection in mice, Basic Res. Cardiol. 104 (2009) 238-246.

[29] J.A. Buege, S.D. Aust, Microsomal lipid peroxidation, Methods Enzymol. 52 (1978) 302-310.

[30] R.L. Levine, D. Garland, C.N. Oliver, et al., Determination of carbonyl content in oxidatively modified proteins, Methods Enzymol. 186 (1990) 464-478.

[31] H. Aebi, Catalase in vitro, Methods Enzymol. 105 (1984) 121-126.

[32] S. Sarban, A. Kocyigit, M. Yazar, U.E. Isikan, Plasma total antioxidant capacity, lipid peroxidation, and erythrocyte antioxidant enzyme activities in patients with rheumatoid arthritis and osteoarthritis, Clin. Biochem. 38 (2005) 981-986.

[33] D. Ricart-Jané, M. Llobera, M.D. López-Tejero, Anticoagulants and other preanalytical factors interfere in plasma nitrate/nitrite quantification by the Griess method, Nitric Oxide 6 (2002) 178-185.

[34] M.M. Bradford, A rapid and sensitive method for the quantitation of microgram quantities of protein utilizing the principle of protein dye-binding, Anal. Biochem. 7 (1976) 248-254.

[35] M. Gleeson, Immune function in sport and exercise, J. Appl. Physiol. 103 (2007) 693-699.

[36] W. Savino, D.M. Villa-Verde, D.A. Mendes-da-Cruz, et al., Cytokines and cell adhesion receptors in the regulation of immunity to Trypanosoma cruzi, Cytokine Growth Factor Rev. 18 (2007) 107-124.

[37] M.B. Soares, R.S. de Lima, L.L. Rocha, Gene expression changes associated with myocarditis and fibrosis in hearts of mice with chronic chagasic cardiomyopathy, J. Infect. Dis. 202 (2010) 416-426.

[38] S. Adamopoulos, J. Parissis, D. Karatzas, et al., Physical training modulates proinflammatory cytokines and the soluble Fas/soluble Fas ligand system in patients with chronic heart failure, J. Am. Coll. Cardiol. 39 (2002) 653-663.

[39] R.T. Gazzinelli, I.P. Oswald, S. Hieny, S.L James, A. Sher, The microbicidal activity of interferon-gamma-treated macrophages against Trypanosoma cruzi involves an Larginine-dependent, nitrogen oxide-mediated mechanism inhibitable by interleukin-10 and transforming growth factor-beta, Eur. J. Immunol. 22 (1992) 2501-2506.

[40] B.A. Kingwell, Nitric oxide-mediated metabolic regulation during exercise: effects of training in health and cardiovascular disease, FASEB J. 14 (2000) 1685-1696.

[41] J.J. Wen, N.J. Garg, Mitochondrial generation of reactive oxygen species is enhanced at the Qo site of the complex III in the myocardium of Trypanosoma cruzi-infected mice: beneficial effects of an antioxidant, J. Bioenerg. Biomembr. 40 (2008) 587-598.

[42] S. Gupta, V. Bhatia, J.J. Wen, Y. Wu, M.H. Huang, N.J. Garg, Trypanosoma cruzi infection disturbs mitochondrial membrane potential and ROS production rate in cardiomyocytes, Free Radic. Biol. Med. 47 (2009) 1414-1421.

[43] S. Gupta, J.-J. Wen, N.J. Garg, Oxidative stress in Chagas disease, Inter. Perspect. Infect. Dis ID190354 (2009) 1-8.

[44] J.J. Wen, G. Vyatkina, N.J. Garg, Oxidative damage during chagasic cardiomyopathy development: role of mitochondrial oxidant release and inefficient antioxidant defense, Free Radic. Biol. Med. 37 (2004) 1821-1833.

[45] J.J. Wen, P.C. Yachelini, A. Sembaj, R.E. Manzur, N.J. Garg, Increased oxidative stress is correlated with mitochondrial dysfunction in chagasic patients, Free Radic. Biol. Med. 41 (2006) 270-276.

[46] A.M. Niess, H.H. Dickhuth, H. Northoff, E. Fehrenbach, Free radicals and oxidative stress in exercise-immunological aspects, Exerc. Immunol. Rev. 5 (1999) 22-56.

[47] R. Pérez-Fuentes, J.F. Guégan, C. Barnabé, et al., Severity of chronic Chagas disease is associated with cytokine/antioxidant imbalance in chronically infected individuals, Int. J. Parasitol. 33 (2003) 293-299.

[48] B. Halliwell, J.M.C. Gutteridge, Free Radical in Biology and Medicine, third ed. Oxford University Press, Oxford, 1999. 